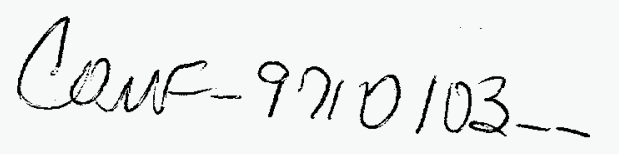

\title{
A COMPARATIVE EVALUATION OF IONSIV® IE-911 AND CHABAZITE ZEOLITE FOR THE REMOVAL OF RADIOSTRONTIUM AND CESIUM FROM WASTEWATER
}

\author{
D. T. Bostick, S. M. DePaoli, and B. Guo
}

Chemical Technology Division

Oak Ridge National Laboratory*

Oak Ridge, Tennessee 37831-6201

To be published in the Proceedings of the

Tenth Symposium on Separation Science and Technology for Energy Applications
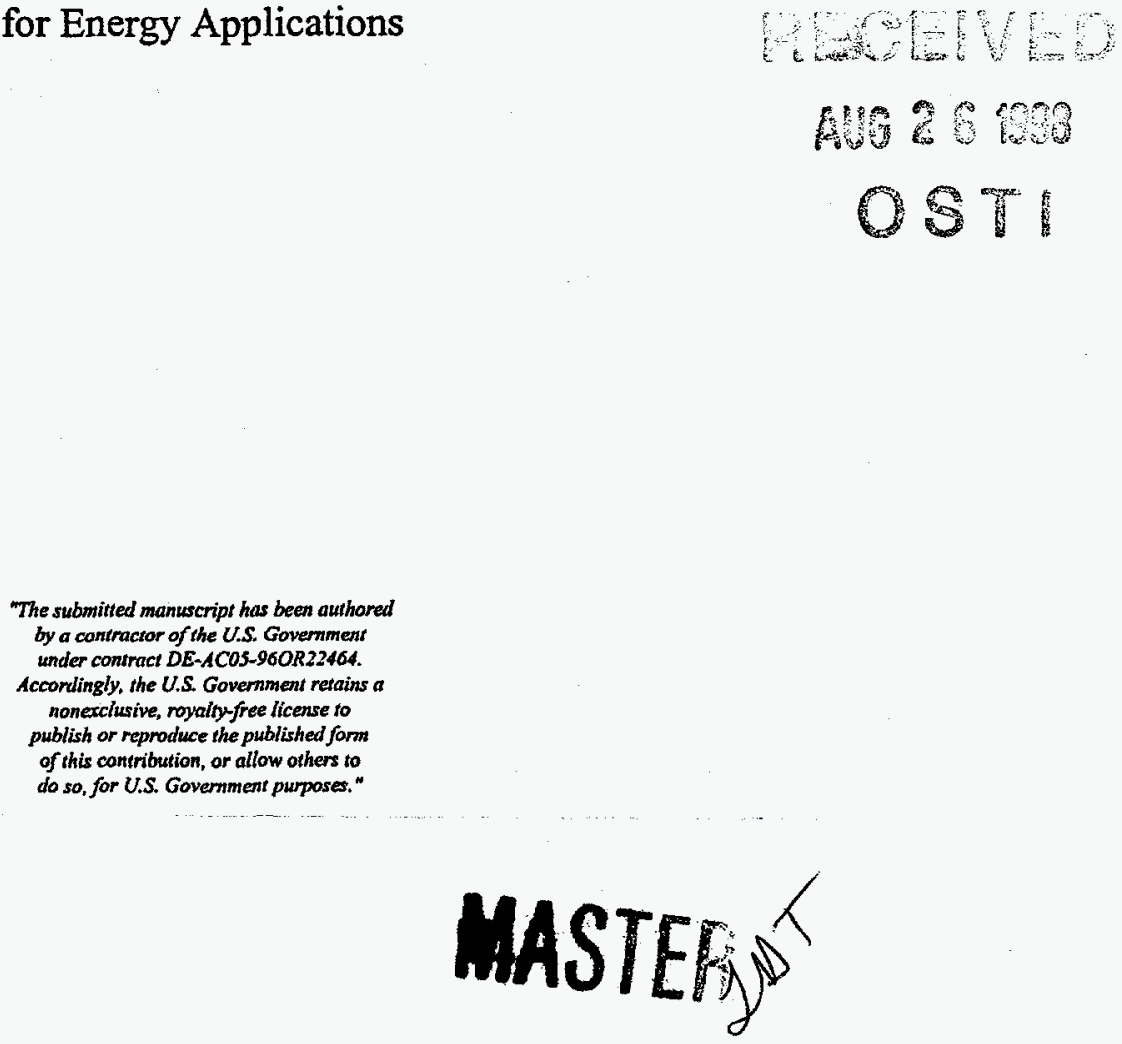

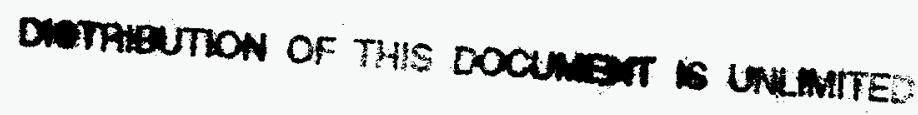

*Managed by Lockheed Martin Energy Research Corp. under contract DE-AC0596OR22464 with the U.S. Department of Energy. 


\section{DISCLAIMER}

This report was prepared as an account of work sponsored by an agency of the United States Government. Neither the United States Government nor any agency thereof, nor any of their employees, make any warranty, express or implied, or assumes any legal liability or responsibility for the accuracy, completeness, or usefulness of any information, apparatus, product, or process disclosed, or represents that its use would not infringe privately owned rights. Reference herein to any specific commercial product, process, or service by trade name, trademark, manufacturer, or. otherwise does not necessarily constitute or imply its endorsement, recommendation, or favoring by the United States Government or any agency thereof. The views and opinions of authors expressed herein do not necessarily state or reflect those of the United States Government or any agency thereof. 


\section{DISCLAIMER}

Portions of this document may be illegible in electronic image products. Images are produced from the best available original document. 


\title{
A COMPARATIVE EVALUATION OF IONSTV IE-911 AND CHABAZITE ZEOLITE FOR THE REMOVAL OF RADIOSTRONTIUM AND CESIUM FROM WASTEWATER
}

\author{
D. T. Bostick, S. M. DePaoli, and B. Guo \\ Chemical Technology Division \\ Oak Ridge National Laboratory \\ P. O. Box 2008 \\ Oak Ridge, Tennessee 37831-6201
}

\begin{abstract}
Natural chabazite zeolite was selected as the baseline treatment technology for the removal of fission products, namely ${ }^{90} \mathrm{Sr}$ and ${ }^{137} \mathrm{Cs}$, from near-neutral-pH process wastewater and groundwater. The sorbent IONSIV ${ }^{\otimes}$ IE-911, a crystalline silicotitanate manufactured by UOP, was recently tested in this capacity and found to compare extremely well against the baseline material. This paper presents and compares the results of similar batch and column tests performed using both materials, and summarizes the physical and chemical characteristics of the sorbents.
\end{abstract}

\section{INTRODUCTION}

Many DOE facilities generate process wastewater that is contaminated with ${ }^{90} \mathrm{Sr}$ and ${ }^{137} \mathrm{Cs}$, and/or are responsible for processing groundwater in order to lower levels of these radioactive constituents to acceptable limits. In most cases, the treatment option of choice is ion-exchange, and this material has generally been a type of natural zeolite. Through a grant from the DOE Efficient Separations and Processing (ESP) Crosscut EM-50 Program, several new, promising materials have been evaluated for their capacity to remove these fission products from simulated and actual wastewaters. The materials are evaluated for their capacity in removing ${ }^{90} \mathrm{Sr}$ and ${ }^{137} \mathrm{Cs}$ in the presence of competing alkaline and alkalineearth cations, which are sometimes present in the waste at levels exceeding 1 million times the concentration of the target radioactive species. Therefore, the most important measure of the success of a

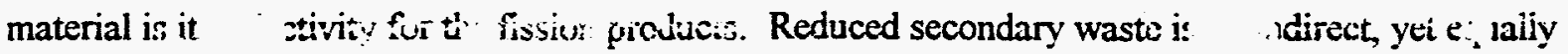


important result of a more selective ion-exchanger.

As mentioned, the most common material used in treating wastewater for the removal of fission products is natural zeolite; the baseline material in this study is chabazite zeolite obtained from GSA Resources. Crystalline silicotitanate (CST), developed at Texas A\&M and Sandia National Laboratories (SNL) for the treatment of high-sait, high pH tank waste, has shown a remarkable ability to remove strontium and cesium from near-neutrai-pH wastewater in the presence of other competing cations. It is now commercially available through UOP in a granular (IONSIV ${ }^{\circ}$ IE-910) or pelletized form (IONSIV IE-911). Test results using the zeolite and IONSIV ${ }^{\star}$ E-911 in batch and column configurations are presented and compared here.

\section{EXPERIMENTAL}

\section{Batch Testing}

Process wastewater simulant was prepared by adding dry chemicals to $100 \mathrm{~L}$ volumes of nanopure water and adjusting the $\mathrm{pH}$ of the column feed by sparging $\mathrm{CO}_{2}$ gas into the solution for about an hour. The $\mathrm{pH}$ of the solution dropped to 5 , which enhanced the solubility of the added chemicals., However, the $\mathrm{pH}$ stabilized at a value of 7 after equilibrating for a few days to match that of the simulant used in batch testing. The solution was filtered with a $0.45-\mu \mathrm{m}$ Supor ${ }^{\mathrm{TM}}$ filter membrane recommended by the vendor for the clarification of groundwater samples. Stable strontium and cesium were added to the simulant at this point. A sample of the final simulant solution was then analyzed for total metals by ICP. The ${ }^{85} \mathrm{Sr}$ and ${ }^{137} \mathrm{Cs}$ tracers were added to $20-\mathrm{L}$ aliquots of the feed solution; 2-mL samples from each aliquot were retained to determine the initial activity of the feed solution.

Sorption measurements were made in long-term batch equilibrium tests. The solutions and exchanger are contacted in screw-cap polycarbonate centrifuge tubes by mixing on a Labquake ${ }^{\mathrm{TM}}$ shaker, which rocks the samples from $-45^{\circ}$ to $+45^{\circ}$ from horizontal at 20 cycles per minute. Three samples were included in each data point. Solution volumes were determined from the weight and density of the samples. The sorbent was weighed directly and added to the tubes. At the conclusion of the equilibration period, the tubes were centrifuged for $30 \mathrm{~min}$ at 5000 relative centrifugal force (rcf). The solutions were clarified further by filtering the centrifuged supernate using a plastic syringe fitted with a $0.2-\mu \mathrm{m}$-pore nylon membranè filter.

The extent of strontium and cesium removal was determined by tracing the samples with ${ }^{85} \mathrm{Sr}$ and

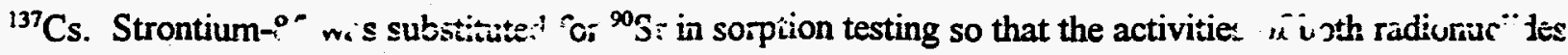


could be counted with a Canberra Series 90 Gamma Spectrometer. The 2-mL samples were counted for $1000 \mathrm{~s}$ in a germanium well detector. Data for ${ }^{85} \mathrm{Sr}$ were corrected for the interference of ${ }^{137} \mathrm{Cs}$ at the 514 $\mathrm{keV}$ peak by using a linear regression line developed with ${ }^{137} \mathrm{Cs}$ standards. Competing cation concentrations in nonradiaactive solutions were determined using a Thermo Jarrel Ash IRIS/CID ICP spectrophotometer on companion untraced experiments. A Perkin-Elmer 5000 atomic absorption (AA) spectrophotometer was used to characterize the cation content of radioactive solutions.

\section{Column Testing}

Column testing will define the sorption characteristics of a material under dynamic flow conditions. The dimensions of a sorbent column were selected primarily on the basis of the diameter of the average sorbent particle.' Although the optimum column diameter should be at least 40 times greater than the average particle diameter (typically $0.059 \mathrm{~cm}$ or $30 \mathrm{mesh}$ ), a factor of 20 was deemed adequate for testing. A $1-\mathrm{cm}$ column diameter meets these requirements and was used for comparative testing of the sorbents. The optimum length of the column should be greater than or equal to 4 times the column diameter; the typical column aspect ratio for testing is between 4 and 5 . Approximately $2 \mathrm{~g}$ of preconditioned sorbent were packed in the 1-cm-ID columns, resulting in a bed volume of $3.85 \mathrm{~mL}$ for each test.

The CST column was prepared by slowly adding prepared sorbent from a weighed container to a $1-\mathrm{cm}$ column containing a known volume of water. The sorbent was added to the column to a bed depth of $4.5 \mathrm{~cm}$. The dry sorbent container was reweighed to determine the weight of sorbent added to the column. Excess water above the column bed was collected and weighed. The difference between the initial water volume in the column and the volume of water displaced by sorbent represents the pore volume of the sorbent column. The pore fraction is equivalent to the measured pore volume of the $1-\mathrm{cm}$ column divided by the column volume, calculated on the basis of a $4.5-\mathrm{cm}$ bed height.

A peristaltic pump was used to transfer the traced simulant through a second $0.45-\mu \mathrm{m}$ Supor TM filter membrane into the base of the sorbent column (Fig. 1). The flow rate of simulant feed was set at 1.2 $\mathrm{mL} / \mathrm{min}$ (about $19 \mathrm{BV} / \mathrm{h}$ ) to maintain a linear flow velocity similar to that of successful earlier column tests. The feed was introduced at the bottom of the column to maximize contact of the solution and sorbent within the column. An automatic fraction collector was used to collect the column effluent over 6 -h periods (or $460 \mathrm{~mL}$ per fraction), and later in the test, at 8-h intervals. Aliquots of each fraction were acidified and submitted for ICP analysis of competing cations through breakthrough of these species. The nuclide content of each fraction was determiner using gamma spectrometry. 


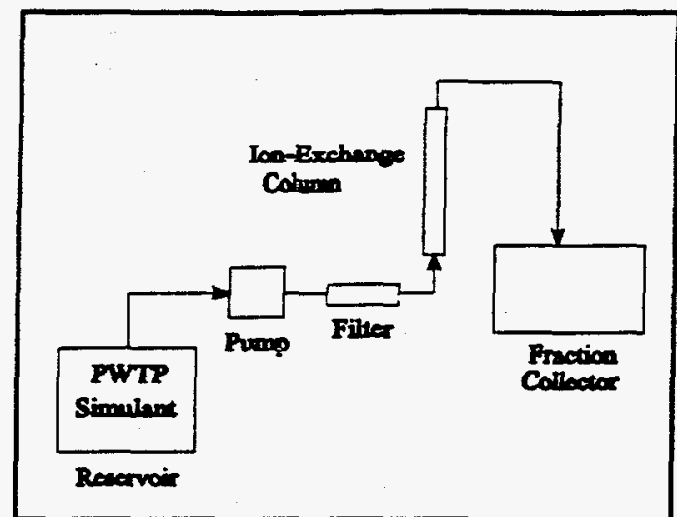

Figure 1. Flow diagram for column test.

The test results were used in the following equations:

$$
\begin{gathered}
\text { Decontamination factor, } D F=\frac{G_{i}}{G_{f}}, \\
\text { Sorption ratio, } R_{s}(L / k g)=\frac{\left(G_{i}-G_{f}\right) V}{G_{f} W},
\end{gathered}
$$

$$
\text { Final solution concentration, } C_{f}(m e q / L)=\frac{C_{i} G_{f}}{G_{i}} \text {, }
$$

and

$$
\text { Final concentration on exchanger, } C_{x}(m e q / k g)=C_{f} R_{s} \text {. }
$$

where:

$G_{i}=$ gamma count rate of the initial solution;

$G_{f}=$ gamma count rate of the final solution;

$V=$ volume of the solution treated, $\mathrm{mL}$;

$W=$ exchanger weight, $\mathrm{g}$;

$C_{i}=$ concentration in initial solution, meñ $/ \mathrm{L}$;

$C_{f}=$ concentration in nüul solution, $\mathrm{meg} / \mathrm{kg}$. 
The sorption ratio $\left(R_{3}\right)$ is equivalent to the distribution coefficient $\left(K_{\mathrm{d}}\right)$ if equilibrium conditions are assumed. The exchanger weight is reported on a dry-weight basis by correcting for moisture content of the sorbent in order to make direct comparison of sorption efficiency among sorbent materials.

\section{RESULTS AND DISCUSSION}

\section{Physical Characterization of Sorbents}

A number of physical parameters are important in assessing the performance of a given sorbent. Some of these characteristics include the sorbent density, surface moisture content, surface area, pore size, pore volume, particle size, degree of particle swelling, and mechanical stability. Table 1 summarizes the available physical data for each of the sorbents. Much of this information is available for the baseline zeolite sorbent, primarily through the manufacturer's product literature.

Table 1. Physical and chemical parameters for zeolite and CST.

\begin{tabular}{|c|c|c|}
\hline Parameter & Chabazite zeolite $^{a}$ & $\begin{array}{l}\text { Crystalline silicotitanate } \\
\text { (IONSIV } \text { IE-911) }^{\circ}\end{array}$ \\
\hline Source & GSA Resources, Inc. & UOP \\
\hline Particle density $\left(\mathrm{g} / \mathrm{cm}^{3}\right)$ & 1.73 & 2.0 \\
\hline Surface moisture, wt\% & 7.1 & 6.0 \\
\hline Pore size, $\AA$ & $4.1-3.7$ & $4.0^{b}$ \\
\hline Total pore volume, $\mathrm{cm}^{3} / \mathrm{g}$ & 0.468 & $0.24^{c}$ \\
\hline Dry particle size, $\mu \mathrm{m}$ (as-received) & $484 \pm 223$ & $409 \pm 111$ \\
\hline Wet particle size, $\mu \mathrm{m}$ (pretreated) & $575 \pm 156$ & $418 \pm 113$ \\
\hline Sodium content, w/w\% & 6.2 & 2.13 \\
\hline Ion-exchange capacity, meq/g & 2.2 & 2.5 \\
\hline $\begin{array}{l}\text { Pretreatment needs for use in treating } \\
\text { near-neutral-pH wastewater }\end{array}$ & $\begin{array}{l}\text { sieve, wash with } 2 M \mathrm{MaCl} \\
\text { wash with } \mathrm{H}_{2} \mathrm{O} \text {, air dry }\end{array}$ & $\begin{array}{l}\text { sieve, wash with } \mathrm{H}_{2} \mathrm{O} \text {, wash } \\
\text { with } 0.1 \mathrm{MHCl}\end{array}$ \\
\hline \multicolumn{3}{|c|}{$\begin{array}{l}\text { "Cabsorb-ZS500A product literature, GSA Resources, Inc., Cortaro, Arizona. } \\
\text { 'Z. Zeng, et. al., "Ion-exchange of Group I Metals by Hydrous Crystalline Silicotitanates," Ind. Eng. } \\
\text { Chem. Res., 35, 4246-4256 (1996). } \\
\text { cMiller, J. E. and N. E. Brown, "Development and Properties of Crystalline Silicotitanate (CST) Ion } \\
\text { Exchangers for Radioactive Waste Applications," SANDLA REPORT, SAND97-0771, April 1997. This } \\
\text { is the pore volume of IONSIV" :-.,10. }\end{array}$} \\
\hline
\end{tabular}


Sieve analysis ${ }^{2}$ was used to determine the particle size of engineered CST (IONSIV ${ }^{\circ}$ IE-911, Lot No. 9990968/002). Two forms of CST were sized: (1) the as-received material and (2) CST that has been preconditioned by equilibrating it with $2 \mathrm{MNaCl}$, water rinsed, and air dried. Sieving results indicated that $90 \%$ of the as-received dry sorbent was in the $-30 /+60$ mesh size range; the average particle size, based on pellet volume, was $409 \pm 111 \mu \mathrm{m}$ (Table 1). When the as-received material was wetted, approximately $10 \%$ of the sorbent was removed as fines in the rinse water. Evidently, fines adhere to the larger particles and are not detected separately during dry sieve analysis. The dry particle size of salinewashed CST was $374 \pm 107 \mu \mathrm{m} ; 90 \%$ of the particles were also in the $-30 /+60$ mesh size range. The wet particle sizes of both the as-received and pretreated CST were found to be $415 \mu \mathrm{m}$. The sieve results suggest that once fines are removed, the dry particle size is actually $375 \mu \mathrm{m}$ for both forms of CST. When either form of the sorbent is fully wetted, the volume is approximately $20 \%$ greater.

Additional physical parameters pertinent to IONSIV ${ }^{\circ}$ IE-911 include an approximate pore opening of $4 \AA$, a particle density of $2.0 \mathrm{~g} / \mathrm{cm}^{3}$, and a bulk density of $62.4 \mathrm{lb} / \mathrm{ft}^{3}\left(960 \mathrm{~kg} / \mathrm{m}^{3}\right){ }^{3}$

Results of the sieve analysis for chabazite zeolite indicated that the dry, as-received resin was finer than the stated $-35 /+50$ mesh range. The average dry particle sizes of the combined $-20 /+50$ fractions of the as-received zeolite were $536 \pm 149 \mu \mathrm{m}$, with an average water content of $7.1 \mathrm{wt} \%$. Approximately $2 \%$ fines were produced when the sorbent was pretreated. The average wet-particle size of the pretreated zeolite was $575 \pm 156 \mu \mathrm{m}$. The difference between the average particle size of the wet and dry forms of the zeolite indicated that the volume of the sorbent swelled by a factor of 1.23 , where the wet particle size more accurately reflects the particle size of the sorbent during testing.

\section{Chemical Characterization and Pretreatment of Chabazite Zeolite}

Natural chabazite zeolite was purchased from GSA Resources, Inc. at a cost of $\$ 50 / \mathrm{ft}^{3}$. A stock supply was pretreated to remove the natural strontium present on the as-received zeolite. This pretreatment was accomplished by washing the zeolite with $2 \mathrm{M} \mathrm{NaCl}$, followed by several rinses with deionized water to remove excess sodium ion; thus the natural strontium was displaced, and the zeolite was fully loaded with sodium. The $-20 /+50$ mesh fraction $(300-840 \mu \mathrm{m})$ of the pretreated zeolite represents the reference sorbent for the remaining studies presented here. Sodium content of the as-received zeolite was confirmed to be $6.2 \mathrm{wt} \%$. The exchange capacity of the zeolite was determined to be $2.2 \mathrm{meq} / \mathrm{g}$ zeolite. 


\section{Chemical Characterization and Pretreatment of CST}

CST sorbent can exist in multiple ionic forms. The form of CST undergoing exchange with strontium and cesium is a function of both the sodium ion concentration and the $\mathrm{pH}$ in the waste. In a recent publication, Zheng et al. ${ }^{4}$ defined CST functionality in sodium solutions according to the following equilibrium reactions:

$$
\begin{gathered}
\mathrm{H}^{+}+\mathrm{Na}_{3}-\mathrm{CST}=\mathrm{HNa}_{2}-\mathrm{CST}+\mathrm{Na}^{+} \quad k_{1}=7.7 \times 10^{8}, \\
\mathrm{H}^{+}+\mathrm{HNa}_{2}-\mathrm{CST}=\mathrm{H}_{2} \mathrm{Na}-\mathrm{CST}+\mathrm{Na}^{+} \quad k_{2}=6.1 \times 10^{7},
\end{gathered}
$$

and

$$
\mathrm{H}^{+}+\mathrm{H}_{2} \mathrm{Na}-\mathrm{CST}=\mathrm{H}_{3}-\mathrm{CST}+\mathrm{Na}^{+} \quad k_{3}=7.4
$$

The concentration of each CST form can be rewritten in terms of the preceding equilibrium constants,

$$
\begin{gathered}
{\left[\mathrm{HNa}_{2}-\mathrm{CST}\right]=k_{1} \frac{\left[\mathrm{Na}_{3}-\mathrm{CST}\right]\left[\mathrm{H}^{+}\right]}{\left[\mathrm{Na}^{+}\right]},} \\
{\left[\mathrm{H}_{2} \mathrm{Na}-\mathrm{CST}\right]=k_{2} \frac{\left[\mathrm{HNa}_{2}-\mathrm{CST}\right]\left[\mathrm{H}^{+}\right]}{\left[\mathrm{Na}^{+}\right]}=k_{1} k_{2} \frac{\left[\mathrm{Na}_{3}-\mathrm{CST}\right]\left[\mathrm{H}^{+}\right]^{2}}{\left[\mathrm{Na}^{+}\right]^{2}},}
\end{gathered}
$$

and

$$
\left[\mathrm{H}_{3}-\mathrm{CST}\right]=k_{3} \frac{\left[\mathrm{H}_{2} \mathrm{Na}-\mathrm{CST}\right]\left[\mathrm{H}^{+}\right]}{\left[\mathrm{Na}^{+}\right]}=k_{1} k_{2} k_{3} \frac{\left[\mathrm{Na}_{3}-\mathrm{CST}\right]\left[\mathrm{H}^{+}\right]^{3}}{\left[\mathrm{Na}^{+}\right]^{3}}
$$

and summed in a mass balance equation,

$$
\left.[\mathrm{CST}]=\left[\mathrm{Na}_{3}-\mathrm{CST}\right]+: \mathrm{Ha}-\mathrm{CST}\right] \cdot\left[\mathrm{H}_{2} \mathrm{Na}-\mathrm{CST}\right]+\left[\mathrm{H}_{3}-\mathrm{CST}\right]
$$


The distribution of CST functionality in a given waste matrix can be determined by combining Eqs. (8-11). For example, the fractional contribution of the trisodium form of CST to the overall IONSIV ${ }^{\circ}$ IE-911

functionality can be determined as

$$
\frac{\left[\mathrm{Na}_{3}-\mathrm{CST}\right]}{[\mathrm{CST}]}=\frac{1}{k_{1} \frac{\left[\mathrm{H}^{+}\right]}{\left[\mathrm{Na}^{+}\right]}+k_{1} k_{2} \frac{\left[\mathrm{H}^{+}\right]^{2}}{\left[\mathrm{Na}^{+}\right]^{2}}+k_{1} k_{2} k_{3} \frac{\left[\mathrm{H}^{+}\right]^{3}}{\left[\mathrm{Na}^{+}\right]^{3}}}
$$

Each of the other CST forms can be similarly represented. For typical nuclear tank waste containing $5 \mathrm{M}$ sodium ion and a pH greater than 11, equilibrium calculations indicate that the trisodium CST will be the primary form of CST undergoing exchange (Fig. 2). However, the monosodium form of CST is the primary form of the exchanger in near-neutral wastewater streams (Fig. 3). Even if the total sodium content is as great as $5 \mathrm{M}$, over $98 \%$ of CST will hydrolyze to the monosodium form in a near-neutral, equilibrated solution.

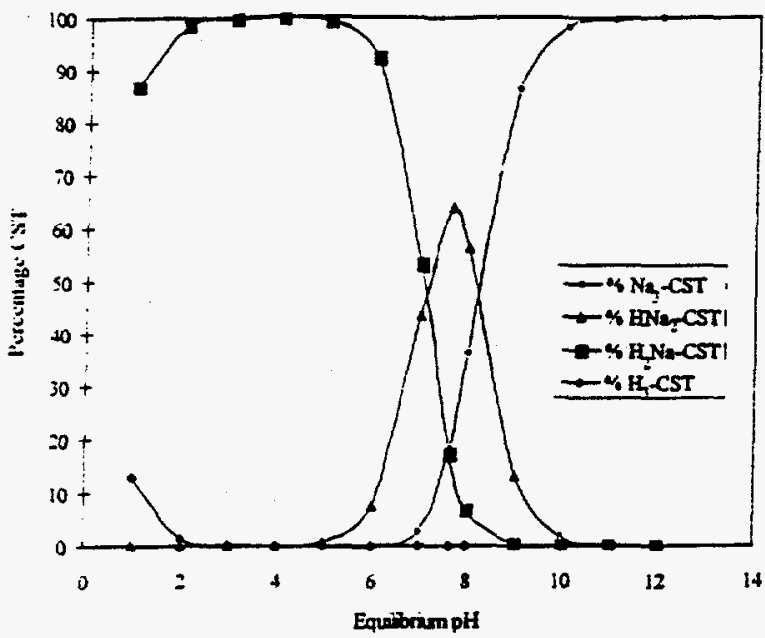

Figure 2. CST functionality in $5 M$ sodium.

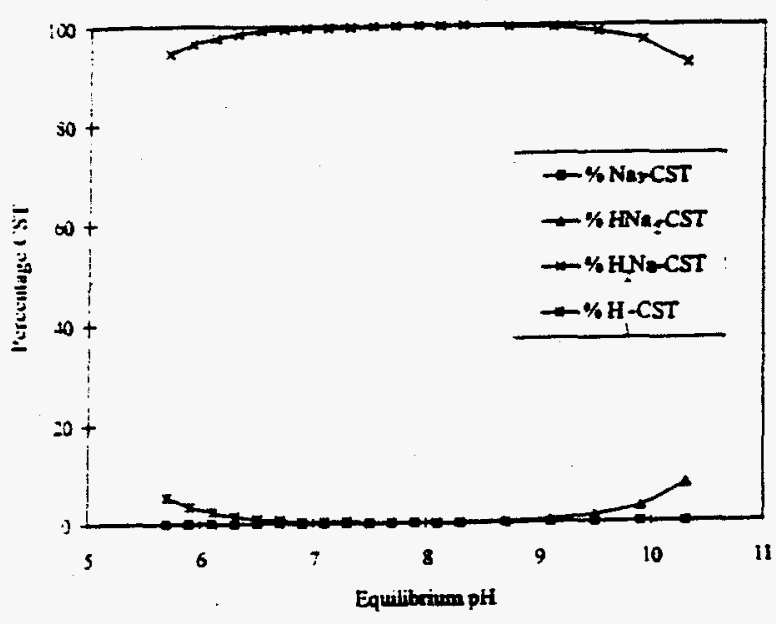

Figure 3. CST functionality in $15 \mathrm{ppm}$ sodium.

The implication of the preceding calculations is that efforts to convert CST to either the trisodium or the trihydrogen form are not particularly effective for wastewater applications. According to directions supplied by UOP, IONSIV IE-911 should be converted to the trisodium form by pretreating the CST with $\mathrm{NaOH}$. Complete 'vin'ersion to the rrisodium CST ensures that the exchanger will ' av. the greatest 
exchange capacity in highly alkaline tank matrices and that the pH of the waste is not altered by any exchange of hydrogen on the CST with sodium ion present in the waste solution. However, in near-neutralpH waste matrices, the formation of the monosodium CST is highly favored, such that trisodium CST immediately hydrolyzes and elevates the $\mathrm{pH}$ of the process wastewater. The secondary consequence of CST hydrolysis is the possibility that near-saturation levels of calcium present in groundwater might precipitate as the $\mathrm{pH}$ of the waste increases. Conversely, if the CST is pretreated with $\mathrm{HCl}$ to form trihydrogen CST, monosodium CST is rapidly formed by the uptake of sodium from process wastewater and the release of hydrogen ion into the waste stream.

The presence of multiple cationic forms of CST must be considered in interpreting laboratory data intended to chemically characterize the inorganic sorbent. According to UOP product literature, the asreceived sorbent contains $\mathrm{Na}_{2} \mathrm{O}, \mathrm{SiO}_{2}, \mathrm{TiO}_{2}$ and proprietary oxides.' The cationic content was determined by ICP indicating the as-received IONSIV IE-911 contained $2.13 \pm 0.2 \mathrm{wt} \% \mathrm{Na}(0.93 \mathrm{meq} / \mathrm{g})$; only traces of $\mathrm{Mg}$ and $\mathrm{Ca}$ were observed. Potassium was not detected. For comparison purposes, IONSIV IE-910, the powder form of CST, contains $10.5-11.5 \mathrm{wt} \%$ (4.8 meq/g) ion-exchangeable sodium. ${ }^{3}$

Two procedures were used to remove fines and convert the as-received IONSIV ${ }^{\circ}$ IE-911 to a single cationic form. The UOP procedure was modified by pretreating the sorbent with $2 \mathrm{M} \mathrm{NaCl}$ rather than $\mathrm{NaOH}$. It was felt that alkaline preconditioning might result in a basic sorbent that would precipitate alkaline earth metals when the sorbent was used in process wastewater. Following a saline pretreatment procedure that was used previously for zeolite, preconditioned IONSIV IE-911 was then rinsed several times with nanopure water to remove excess saline. The sodium content of the saline-washed CST, which will be referred to as Sodium-CST, was 3.4 wt \% or 1.36 meq Na/g CST. Batch testing results summarized in this report were performed using the Sodium-CST sorbent. In light of the recently published equilibrium reactions [Eqs. (5-7)], it is evident that this preconditioning method produces primarily $\mathrm{H}_{2} \mathrm{Na}-\mathrm{CST}$, rather than $\mathrm{Na}_{3}-\mathrm{CST}$. This conclusion is supported by the fact that the sodium content is approximately one-third that of the trisodium form of CST prepared by Zheng et al. ${ }^{4}$ Additionally, when the preconditioned sorbent was introduced into near-neutral-pH simulant, it consistently yielded a basic solution, as the sodium on the CST was displaced with hydrogen in solution. Because there is little difference between the sodium content of the as-received and preconditioned CST, it can be assumed that IONSIV IE-911 is received primarily in the $\mathrm{H}_{2} \mathrm{Na}-\mathrm{CST}$ form.

The sorbent used in the column test was prepared by contacting as-received IONSIV IE-911 with LM HCl. The comm-ed CST was then rinsed with nanopure water until the $\mathrm{pH}$ of th resulting rinste was 
near neutral. The hydrogen-form CST was air dried; the final sodium content was less than $0.02 \mathrm{wt} \%$. According to the stated equilibria, the acid-washed sorbent, henceforth referred to a Hydrogen-CST, should be in the trihydrogen form.

The exchangeable hydrogen content for both the Sodium-CST and Hydrogen-CST preparations was determined by contacting $0.1 \mathrm{~g}$ of the preconditioned CST with $5 \mathrm{M} \mathrm{NaCl}$. After five saline contacts, a total of $1 \mathrm{meq} \mathrm{H} / \mathrm{g}$ was generated from Sodium-CST; linear extrapolation of the data to negligible $\mathrm{H}_{3}-$ CST content suggests that the original Sodium-CST preparation contains $1.18 \mathrm{meq} / \mathrm{g}$ exchangeable hydrogen, in addition to the $1.36 \mathrm{meq} / \mathrm{g}$ exchangeable sodium. The combined exchangeable cation content indicates that the Sodium-CST in near-neutral-pH applications has a total ion-exchange capacity of 2.5 meq/g sorbent.

Similar data calculations indicate that the Hydrogen-CST generates $10.75 \mathrm{meq} \mathrm{H} / \mathrm{g}$ after five contacts with $5 \mathrm{M} \mathrm{NaCl}$. A logarithmic extrapolation of the data to negligible $\mathrm{H}_{3}-\mathrm{CST}$ suggests that the original Hydrogen-CST preparation contains $10.8 \mathrm{meq} / \mathrm{g}$ exchangeable hydrogen. This value is four times greater than the combined total of exchangeable sodium and hydrogen in the Sodium-CST. The elevated value might indicate that additional sodium exchange sites were created by treating the CST and binder with strong hydrochloric acid. Anthony et al. ${ }^{5}$ found that powdered CST resisted acid dissolution if the $\mathrm{pH}$ was greater than 2. Pretreatment of the IONSIV ${ }^{\circ}$ IE-911 with a less concentrated acid $(0.1 \mathrm{M} \mathrm{HCl})$ may be advisable to produce the trihydrogen form of CST.

\section{Strontium and Cesium Ion-Exchange Capacity/Ratio on CST}

Multiple functionality of CST complicated the determination of ion-exchange capacity of the sorbent for cesium and strontium. The cesium cation-exchange capacity was estimated by two procedures. The as-received IONSIV IE-911 was contacted with $0.1 \mathrm{M}$ cesium chloride $\left(\mathrm{CsCl}_{2}\right)$ that had been traced with ${ }^{137} \mathrm{Cs}$. Final cesium and sodium contents, determined by cesium activity and atomic absorption, respectively, indicate that $1.69 \pm 0.09 \mathrm{meq} / \mathrm{g}$ cesium was sorbed per $1.48 \pm 0.15 \mathrm{meq} / \mathrm{g}$ sodium exchanged. Similarly, $1.06 \pm 0.01 \mathrm{meq} / \mathrm{g}$ cesium was sorbed per $1.03 \pm 0.03 \mathrm{meq} / \mathrm{g}$ sodium exchanged when the Sodium-CST was contacted with $0.01 \mathrm{MCsCl}_{2}$. The approximate $1: 1$ exchange of cesium for sodium is in agreement with the description of cesium sorption on CST presented by Zheng et al. ${ }^{4}$ Cesium primarily exchanges with only one of the sites on CST, and only if that site is in the sodium form. Zheng represented the chemical equilibrium reaction as 


$$
\mathrm{Cs}^{\bullet}+\mathrm{H}_{2} \mathrm{Na}-\mathrm{CST}=\mathrm{H}_{2} \mathrm{Cs}-\mathrm{CST}+\mathrm{Na}^{+} \quad k_{4}=1.5 \times 10^{7}
$$

The cesium ion-exchange capacity was also determined by mixing duplicate $0.5-\mathrm{g}$ samples on a Labquake shaker overnight with $25 \mathrm{~mL}$ of $50 \mathrm{ppm} \mathrm{CsCl}$ (pH 5.45) traced with ${ }^{137} \mathrm{Cs}$. At the end of a 24-h contact, the final $\mathrm{pH}$ values of the solutions were determined and the samples were then centrifuged at 5000 relative centrifugal force (rcf) for $45 \mathrm{~min}$. The clarified solutions were removed, counted for cesium activity, and submitted for AA analysis. The separated CST was then contacted with fresh $\mathrm{CsCl}$ solution for at least $24 \mathrm{~h}$. Multiple contacts were continued until the cesium concentration of the equilibrated solutions was equivalent to the initial concentration. A total of 11 solution contacts (Fig. 4) were made, in which the sum of $0.8 \mathrm{meq} / \mathrm{g}$ cesium sorbed to the CST; $0.96 \mathrm{meq} / \mathrm{g}$ sodium and $0.0001 \mathrm{meq} / \mathrm{g}$ hydrogen were released into the solution. Cesium data at the two highest sodium concentrations in Fig. 4 represent the solution composition of the first two $50-\mathrm{ppm} \mathrm{CsCl}$ contacts. The elevated $\mathrm{pH}$ values of these samples indicate that sodium release is the result of both CST hydrolysis and cesium exchange on $\mathrm{H}_{2} \mathrm{Na}-\mathrm{CST}$. Beyond the third contact $(0.15 \mathrm{M}$ sodium), the final $\mathrm{pH}$ is more acidic than that of the initial $50-\mathrm{ppm} \mathrm{CsCl}$ solution. At this point in the study, cesium appears to be replacing primarily sodium ion-and, only to a very limited extent, hydrogen ion.

For sorption data involving a single ion-exchange reaction of the general form

$$
m M_{(a q)}^{n+}+n A_{(s)}^{m+}=m M_{(s)}^{n+}+n A_{(a q)}^{m+}
$$

the equilibrium sorption ratio, or distribution coefficient $\left(K_{d}\right)$, is related to the concentration of exchanging ion by the following equation:

$$
\frac{d \log \left[K_{d}\right]_{M}}{d \log \left[A^{m+}\right]_{a q}}=-\frac{n}{m},
$$

where $\left[K_{\mathrm{d}}\right]_{\mathrm{M}}$ represents the equilibrium sorption ratio of cesium, $\left[A^{\mathrm{m}+}\right]_{\mathrm{sq}}$ represents the aqueous concentration of sodium, and $n / m$ signifies the charge ratio of cesium to sodium. Equation (15) was plotted and used to confirm a 1:1 arrhange between $\mathrm{Cs}$ and $\mathrm{Na}$ on chabazite; ideally, the slope of ${ }^{\text {th }}$; plot should 
be a value of -1 for this situation. In the case of sodium-cesium exchange on $\mathrm{H}_{2} \mathrm{Na}-\mathrm{CST}$ (Fig. 4), multiple breaks in the plot were seen, suggesting the multiplicity of exchange reactions that actually take place in $50 \mathrm{ppm} \mathrm{CsCl}$. No portion of the cesium data can be solely attributed to cesium sorption on monosodium CST, and, therefore, no ion-exchange ratio can be calculated from this form of data treatment.

Strontium chemical equilibria have not been fully defined for highly alkaline wastes, for which the pertinent sorbing species would be the strontium hydroxide cation $\left(\mathrm{SrOH}^{+}\right)$. Strontium exists as the unassociated divalent cation in near-neutral-pH wastes streams; this was verified through the use of the Environmental Protection Agency's (EPA) public domain program - MINTEQ. ${ }^{6}$ Again, no chemical equilibria have yet been established between the $\mathrm{Sr}(\mathrm{II})$ cation and $\mathrm{H}_{2} \mathrm{Na}-\mathrm{CST}$. Duplicate samples of asreceived IONSIV IE-911 was contacted with $50 \mathrm{ppm} \mathrm{SrCl}_{2}$ (pH 5.44) to determine the strontium ionexchange capacity. After 12 contacts with the strontium solution, a total of $1.05 \mathrm{meq} / \mathrm{g}$ strontium was sorbed, while $1.3 \mathrm{meq} / \mathrm{g}$ sodium and $0.0001 \mathrm{meq} / \mathrm{g}$ hydrogen were released. Fig. 5 represents the final sodium concentration after each contact for the duplicate samples. All final solutions were $0.6-0.8 \mathrm{pH}$ units more acidic than the initial $50-\mathrm{ppm} \mathrm{SrCl}_{2}$ solution, indicating a more complex equilibrium than just sodium displacement. As can be seen in Fig. 5, the majority of strontium was loaded within the first seven contacts. Between contacts 3 and 7 , the slope of the data is equivalent to -0.1 , which also suggests that some other mechanism besides simple sodium exchange is involved in strontium sorption.

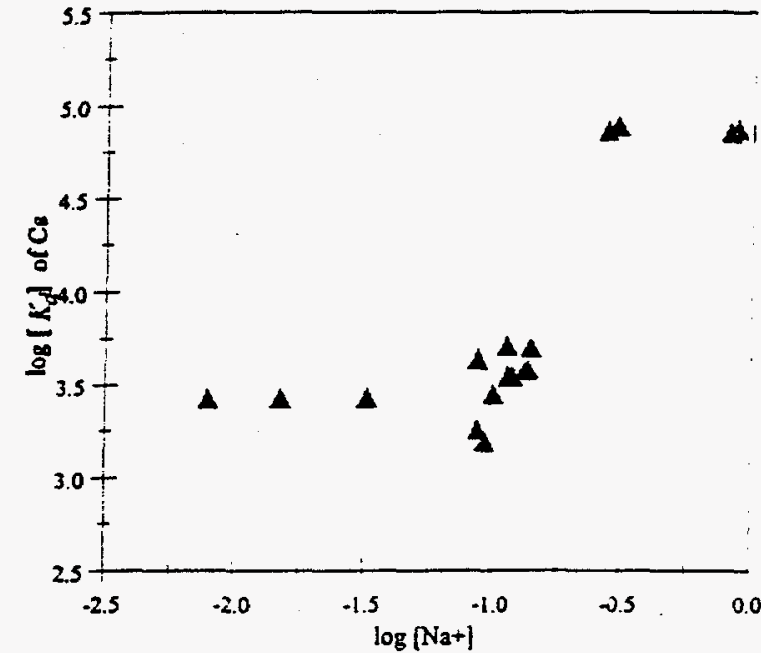
$\because$

Figure 4. Determination of cesium ion-exchange ratio on as-received IONSIV ${ }^{\circ}$ IE-911.

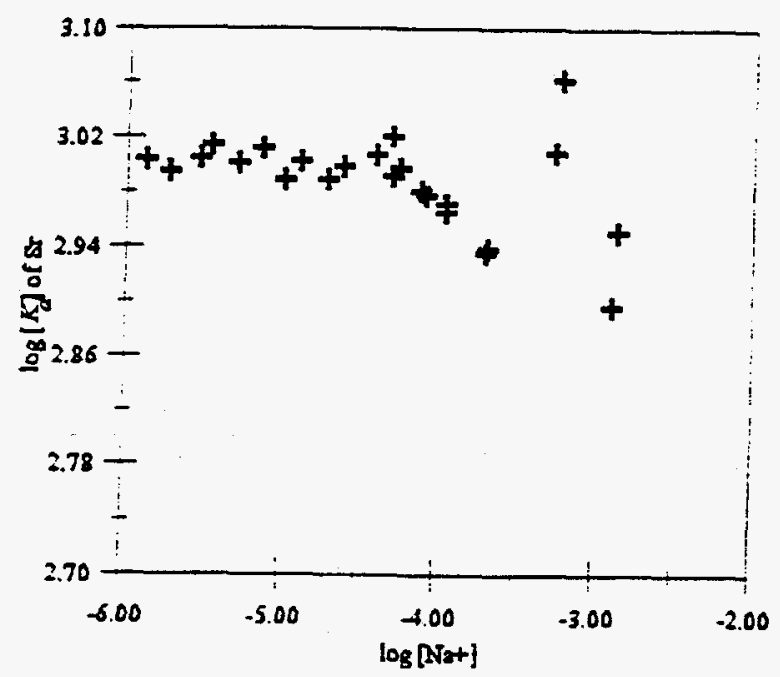

Figure 5. Determination of strontium ionexchange ratio on as-received IONSIV ${ }^{\star}$ IE-911. 


\section{Batch Test Results}

Direct comparison of the two sorbents is valid only if the test conditions are identical and the treated waste streams are identical. In all of the results presented here, the wastewater simulant used had the composition shown in Table 2. This is a simulant based on the process wastewater treated at Oak Ridge National Laboratory's (ORNL) Process Waste Treatment Plant (PWTP), the composition which is also shown in Table 2. This waste stream was choosen to be used as a simulant since it typifies regional DOE wastewater and falls within the regional composition of typical groundwater. 7,8,9,10

Strontium was included in the simulant at a level of $0.1 \mathrm{mg} / \mathrm{L}$ or $0.00228 \mathrm{meq} / \mathrm{L}$ (which included $1 \times 10^{6} \mathrm{~Bq} / \mathrm{L}^{85} \mathrm{Sr}$ tracer) to reflect the average concentration of total strontium in the PWTP feed. This strontium concentration is also typical of process water in the local DOE area and represents a midrange value for groundwater. Both ${ }^{134} \mathrm{Cs}$ and ${ }^{137} \mathrm{Cs}$ are normally absent in local on-site groundwater but are present at an average level of $300 \mathrm{~Bq} / \mathrm{L}$ in PWTP influent. The ${ }^{137} \mathrm{Cs}$ added to the simulant was present at a tracer level of $1.12 \times 10^{6} \mathrm{~Bq} / \mathrm{L}\left(3.4 \times 10^{-4} \mathrm{ppm}, 2.5 \times 10^{-6} \mathrm{meq} / \mathrm{L}\right)$ and reflects the upper limit for cesium activity typical of process wastewater.

Table 2. PWTP actual wastewater and simulant compositions.

\begin{tabular}{lcc}
\hline & \multicolumn{2}{c}{ Concentration $(\mathrm{mg} / \mathrm{L})$} \\
\cline { 2 - 3 } & PWTP, actual & PWTP, simulant \\
\hline $\mathrm{Ca}^{2+}$ & $35-40$ & 45 \\
$\mathrm{Cs}^{+}$ & $9.4 \times 10^{-8}$ & $3.4 \times 10^{-4}$ \\
& $\left(3.0 \times 10^{2} \mathrm{~Bq} / \mathrm{L}\right)$ & $\left(1.12 \times 10^{6} \mathrm{~Bq} / \mathrm{L}\right)$ \\
$\mathrm{K}^{+}$ & $1-3$ & 1.2 \\
$\mathrm{Mg}^{2+}$ & $7-8$ & 8.8 \\
$\mathrm{Na}^{+}$ & $14-30$ & 18.3 \\
$\mathrm{Sr}^{2+}$ (total) & 0.1 & 0.1 \\
$\mathrm{Sr}^{2+}$ (radioactive) & $5.3 \times 10^{-8} \mathrm{as}{ }^{90} \mathrm{Sr}$ & $1.14 \times 10^{-6} \mathrm{as}{ }^{85} \mathrm{Sr}$ \\
& $\left(2.70 \times 10^{2} \mathrm{~Bq} / \mathrm{L}\right)$ & $\left(1.0 \times 10^{6} \mathrm{~Bq} / \mathrm{L}\right)$ \\
$\mathrm{pH}^{-1}$ & & $7-8$ \\
\hline
\end{tabular}




\section{Batch Tests: Chabazite Zeolite}

Natural chabazite zeolite was selected as the benchmark sorbent for removing strontium and cesium from contaminated wastewater. Standard testing of the zeolite included determination of the strontium and cesium sorption rates using batch test procedures. Twenty-four hours was required to achieve sorption equilibrium in $10-\mathrm{mL}$ batch samples containing 0.005 to $0.05 \mathrm{~g}$ of zeolite.

Strontium sorption on pretreated zeolite was observed in PWTP simulant samples in which the total strontium concentration in the initial solution was $0.1 \mathrm{ppm} \mathrm{Sr}$. The strontium sorption isotherm exhibited a curvilinear profile; positive deviations from linearity were observed for strontium loadings greater than $2 \mathrm{meq} / \mathrm{kg}$. The sorption ratio, $R_{\mathrm{s}}$, at low strontium loading on washed zeolite was approximately $17,000 \mathrm{~L} / \mathrm{kg}$, while the comparable $R_{\mathrm{s}}$ on unwashed zeolite was $30 \%$ lower. The difference in the behavior of the two preparations of zeolite indicates the availability of additional sorption sites that were created when the natural strontium was removed during saline washing of chabazite.

Data for strontium sorption on the pretreated zeolite were successfully fit to the Freundlich sorption model. ${ }^{6}$ Cesium sorption was observed in simulant samples containing an initial cesium concentration of $3.4 \times 10^{-4} \mathrm{ppm}$. The sorption isotherm was found to be directly proportional to the concentration of cesium in solution. The $R_{s}$ for cesium on the prepared zeolite was $80,000 \mathrm{~L} / \mathrm{kg}$ as compared with $50,000 \mathrm{~L} / \mathrm{kg}$ on the unwashed zeolite. Cesium sorption data were also fit to a Freundlich sorption model, the results of which implied that the distribution coefficient is essentially constant over the cesium concentration range studied in these tests. ${ }^{\text {? }}$

On completion of testing with the simulant, the sorption of strontium and cesium from actual PWTP feed wastewater was observed on washed zeolite. The sorption profiles of the actual PWTP feed sample were nearly identical to those obtained with the simulant, indicating a close match between the chemical compositions of the simulant and the actual waste stream. Maximum strontium and cesium loadings from the actual wastewater sample (or simulant) onto treated chabazite were calculated to be 24 and $0.17 \mathrm{meq} / \mathrm{kg}$, respectively. Sorption results from these batch studies are summarized for zeolite, and compared to results for crystalline silicotitanate under identical experimental conditions, in Table 3.

\section{Batch Tests: IONSIV IE-911}

Equilibration times, corresponding decontamination factors, and sorption ratios were determined for Sodium-CST by mixing a series of samples containing up to $20 \mathrm{mg}$ of the ion-exchange material in 10 or $15 \mathrm{~mL}$ of the traced process wator simulant (Table 2). 
Table 3. Batch experimental results for sorption of cesium and strontium from PWTP simulant using zeolite and IONSIV ${ }^{\circledR}$ IE-911.

\begin{tabular}{lccccc}
\hline \multirow{2}{*}{$\begin{array}{c}\text { Batch } \\
\text { sorbent parameter }\end{array}$} & \multicolumn{2}{c}{ Cesium } & \multicolumn{2}{c}{ Strontium } \\
\cline { 2 - 3 } & Chabazite zeolite & IONSIV ${ }^{\bullet}$ IE-911 & & Chabazite zeolite & IONSIV IE-911 $^{\circ}$ \\
\hline Sorption ratio, Rs (L/kg) & 17,000 & 95,000 & & 80,000 & $1,300,000$ \\
max. loading, (meq/kg) & 0.17 & 5 & & 24 & 200 \\
maximum DF & 170 & 17,000 & & 80 & 1200 \\
& & & & \\
\hline
\end{tabular}

Cesium and strontium sorption equilibrium times were initially determined on the Sodium-CST. Cesium sorption on the Sodium-CST reached equilibrium at approximately $200 \mathrm{~h}$. Strontium sorption ratios continued to increase, reaching a maximum at just over $500 \mathrm{~h}$. The kinetic characteristics for both $\mathrm{Mg}$ and $\mathrm{Ca}$ are similar to that of Sr. In the process wastewater simulant, it appears that these divalent cations require at least $500 \mathrm{~h}$ to achieve equilibrium concentrations on the solid. Based on the maximum sorption ratios obtained in the equilibrium time experiments, the selectivity preference of the CST in the PWTP simulant is: $\mathrm{Mg}<\mathrm{Ca} \ll \mathrm{Sr}<\mathrm{Cs}$. The material's selectivity for $\mathrm{Na}^{+}$and $\mathrm{K}^{+}$ions was determined in the column tests.

Greater than $99 \%$ of the strontium and cesium were removed from solution by Sodium-CST in under $10 \mathrm{~h}$. Nevertheless, decontamination factors (DFs) and sorption ratios continued to increase slightly with time. The ${ }^{137} \mathrm{Cs}$ DF increased steadily through approximately $50 \mathrm{~h}$, up to 17,000 . The strontium DF continued to increase from a value of 352 at $50 \mathrm{~h}$ to a maximum of 1200 at $525 \mathrm{~h}$.

Batch testing for the removal of cesium and strontium from the PWTP simulant was performed as described previously. Maximum sorption ratios are given in Table 3 . The cesium $R_{s}$ was $1,300,000 \mathrm{~L} / \mathrm{kg}$ in the CST, whereas the comparable value for sorption of cesium on zeolite was $80,000 \mathrm{~L} / \mathrm{kg}$. Likewise, for the strontium the sorption ratio was much higher on the CST as compared to the zeolite: $95,000 \mathrm{~L} / \mathrm{kg}$ on CST and 17,000 L/kg on zeolite.

Maximum loadings for cesium and strontium from PWTP simulant on CST far exceeded those on zeolite (Táble 3). Cesium loading on CST was $5 \mathrm{meq} / \mathrm{kg}$ compared to $0.17 \mathrm{meq} / \mathrm{kg}$ for the zeolite, and a strontium loading of $200 \mathrm{meq} / \mathrm{kg}$ was obtained for CST compared to $24 \mathrm{meq} / \mathrm{kg}$ of Sr on zeolite.

Cesium-sodium and strontium redium binary sorption isotherns were observed for the CST: Thu 
Cs-Na exchange ratio varied between 0.6 and 1 ; the $\mathrm{pH}$ of the equilibrated solutions became more acidic with increasing initial cesium concentration. Again, binary sorption tests reflect the fact that several competing reactions are taking place on the preconditioned CST pellets. Sodium is removed from the CST either by ion-exchange with cesium or by hydrolysis of the sorbent as the sodium is replaced by hydrogen ion in solution. Additionally, cesium appears to exchange with both the sodium sites and, to a lesser extent, with the hydrogen sites (which are formed as a result of CST hydrolysis). The CST hydrolysis reaction will yield a basic sample solution, whereas cesium exchange with available hydrogen sites will yield an acidic solution.

It is the relative extent of CST hydrolysis as compared with the $\mathrm{Cs}-\mathrm{H}$ exchange that defines the equilibrium $\mathrm{pH}$ and the observed $\mathrm{Cs}-\mathrm{Na}$ exchange ratio in a batch sample. At constant initial cesium concentration, the solution pH becomes more basic as the sorbent loading increases. Additionally, the Cs$\mathrm{Na}$ exchange ratio of the solution drops as the sodium concentration increases when more sorbent is available for hydrolysis. At constant sorbent loading, the amount of sodium produced by sorbent hydrolysis remains constant. However, the overall sodium increases concentration linearly with cesium concentration through an ion-exchange process. The equilibrium pH approaches a value of 3 when the initial quantity (milliequivalents) of cesium in solution exceeds the amount of exchangeable sodium on the sorbent. At these high cesium concentrations, the cesium aiso exchanges with hydrogen ion sites and the observed $\mathrm{Cs}-\mathrm{Na}$ exchange ratio increases. The $\mathrm{pH}$ data suggest that at cesium solution concentrations above $1 \mathrm{meg} / \mathrm{L}$, at least $10 \%$ of the cesium exchange on the prepared CST is with hydrogen.

Batch testing was also performed for the Sr-Na binary exchange reaction. After a 600-h mixing time, the pH of the equilibrated solutions ranged from 4.4 at 5-mg loading to 3.9 at $100 \mathrm{mg}$ of sorbent. Strontium sorption onto CST becomes more favorable at elevated strontium solution concentrations. The $\mathrm{Sr}-\mathrm{Na}$ exchange ratio varies from 8.5 for $5 \mathrm{mg}$ loading to 1.5 for $100 \mathrm{mg}$ sorbent. The $\mathrm{Sr}-\mathrm{H}$ ratio is approximately $6 \times 10^{4}$. Ion-exchange with either sodium or hydrogen does not appear to be the only mechanism for strontium removal by CST.

\section{Column Test Results}

\section{Column Test: Baseline Sorbent, Chabazite Zeolite}

Laboratory results identified several sorbent characteristics that might impact the selection of chabazite zeolite by end users. Natural zeolite has a significant heat of hydration. Consequently, steam is initially generated when water is added to a cnl:umn of fresh, dry zeolite and may produce voids in the 
column packing. Natural zeolite is friable; fines are created in the transportation to and charging of a column. With continued column use, zeolite fines and algae cement the column packing so that spent zeolite cannot be easily sluiced from the column. ${ }^{9}$ If it is deemed cost-effective, the natural zeolite should be charged with concentrated saline to displace the natural strontium already present on the sorbent. Care must be taken to remove any excess sodium entrained in the column packing by this pretreatment process, so that it will not affect column performance. If this process is done properly, the lifetime of the zeolite column will be enhanced by about $30 \%$. Some of the positive operational features of this particular sorbent are that the inorganic material does not swell significantly when wetted and the fact that the particle size does not change with compositional fluctuations in the waste matrix. The material is relatively dense; consequently, the column packing is not easily disturbed with changes in column operating pressures. Finally, waste immobilization procedures using grout/cement have already been defined for the final disposal of spent zeolite; and the zeolite cost is extremely low compared to the cost other, new sorbents.

A test with a small zeolite column was completed in order to observe ${ }^{90} \mathrm{Sr}$ and ${ }^{137} \mathrm{Cs}$ breakthrough characteristics under dynamic flow conditions. The performance of the chabazite zeolite for the treatment of process/groundwater samples has been summarized in ORNL topical reports. ${ }^{9}$ The combination of sorption data and column performance served to define zeolite characteristics, as well as to establish standardized testing procedures for the direct comparison of the baseline treatment with emerging sorbent technology in the future. A 1-cm-diam column containing about $2 \mathrm{~g}$ of sodium-modified zeolite was used to treat wastewater simulant. Cation breakthrough was followed by ICP analysis of the effluent, and the radiostrontium and cesium breakthrough was monitored using gamma spectrometry. The zeolite bed in the column was $4.9 \mathrm{~cm}$ deep, and the bed volume was $3.85 \mathrm{~mL}$. At a nominal simulant flow rate of 1.25 $\mathrm{mL} / \mathrm{min}$ (19 bed volumes $(\mathrm{BV}) / \mathrm{h}$ ), the superficial velocity through the bed was $1.6 \mathrm{~cm} / \mathrm{min}$. The void volume was $2.52 \mathrm{~mL}$, and the nominal solution residence time in the column was about $3 \mathrm{~min}$. Details of the test can be found in Reference 7. The column test, which lasted for $120 \mathrm{~d}$, was stopped after 59,000 BV because the cementation of fractured zeolite particles plugged the column.

The breakthrough curves for the major cations are presented in Fig. 6, where the fractional breakthrough $\left(C / C_{0}\right)$, defined as the ratio of the cation concentration in the column effluent to the concentration in the feed, is plotted as a function of the volume of solution passed through the column. The initial effluent fractions (about $2500 \mathrm{BV}$ ) were analyzed by ICP to determine the breakthrough behavior of $\mathrm{Na}, \mathrm{Mg}$, and $\mathrm{Ca}$. The sorption behavior of potansium could not be determined because the potassium 
concentration in all of the feed and effluent samples was at or below the ICP detection limit of $0.1 \mathrm{mg} / \mathrm{L}$. Figure 6 also illustrates the initial displacement of sodium ion from the prepared zeolite as the cations in the feed were sorbed onto the column. Continued sorption of Sr and $\mathrm{Cs}$ onto the zeolite resulted in displacement of $\mathrm{Mg}$ beginning at $250 \mathrm{BV}$ and displacement of $\mathrm{Ca}$ beginning at $500 \mathrm{BV}$. These curves imply that the selectivity of the treated zeolite is as follows: $\mathrm{Ca}>\mathrm{Mg}>\mathrm{Na}$. The fractional breakthrough of these cations stabilized to a value of 1.0 at approximately 800 to $1400 \mathrm{BV}$.

The ${ }^{85} \mathrm{Sr}$ and ${ }^{137} \mathrm{Cs}$ count rates of the effluent fractions were compared with those of the feed solutions to determine breakthrough points, which are shown in Fig. 7. Strontium was first observed in the column effluent at approximately 3000 BV. Fractional breakthrough of 10 and $50 \%$ occurred at 6600 and $15,000 \mathrm{BV}$, respectively. Under these conditions, cesium breakthrough was $1 \%$ after about $15,000 \mathrm{BV}$, $10 \%$ after about $30,000 \mathrm{BV}$, and $50 \%$ after about 50,000 BV. The strontium loading for the zeolite was about 60 meq/kg at 50\% strontium breakthrough; the cesium loading was $0.2 \mathrm{meq} / \mathrm{kg}$ at $50 \%$ cesium breakthrough. These loadings, particularly the strontium loading, are higher than the saturation loadings of about 24 and 0.17 meq/kg measured previously for strontium and cesium, respectively, in batch sorption isotherms. ${ }^{9}$ The breakthrough data were used to construct logarithmic probability plots of strontium and cesium breakthrough vs column throughput. These plots were used to estimate sorption ratios, which are approximately equal to the number of bed volumes at $50 \%$ breakthrough. $^{10}$ The sorption ratios, although slightly lower, were in good agreement with sorption ratios measured ${ }^{7}$ at low loading in batch sorption isotherms:

\begin{tabular}{ccc}
\hline & \multicolumn{2}{c}{ Sorption ratio (L/kg) on chabazite zeolite } \\
\cline { 2 - 3 } Test & Strontium & Cesium \\
\hline Column & 15,800 & 53,000 \\
Batch & 17,000 & 80,000 \\
\hline
\end{tabular}

\section{Column Test: IONSIV ${ }^{\circ}$ IE-911}

Engineered CST (IONSIV IE-911) was received from UOP. A small-column test using the bydrogen form of IONSIV ${ }^{\circ}$ IE-911 was carried out over a period of 10 months, in order to compare its performance to that of the baseline zeolite in removing strontium and cesium from a process wastewater simulant. A description of the IONSIV IE-911 performance under dynamic flow conditions for wastewater treatment follows. 


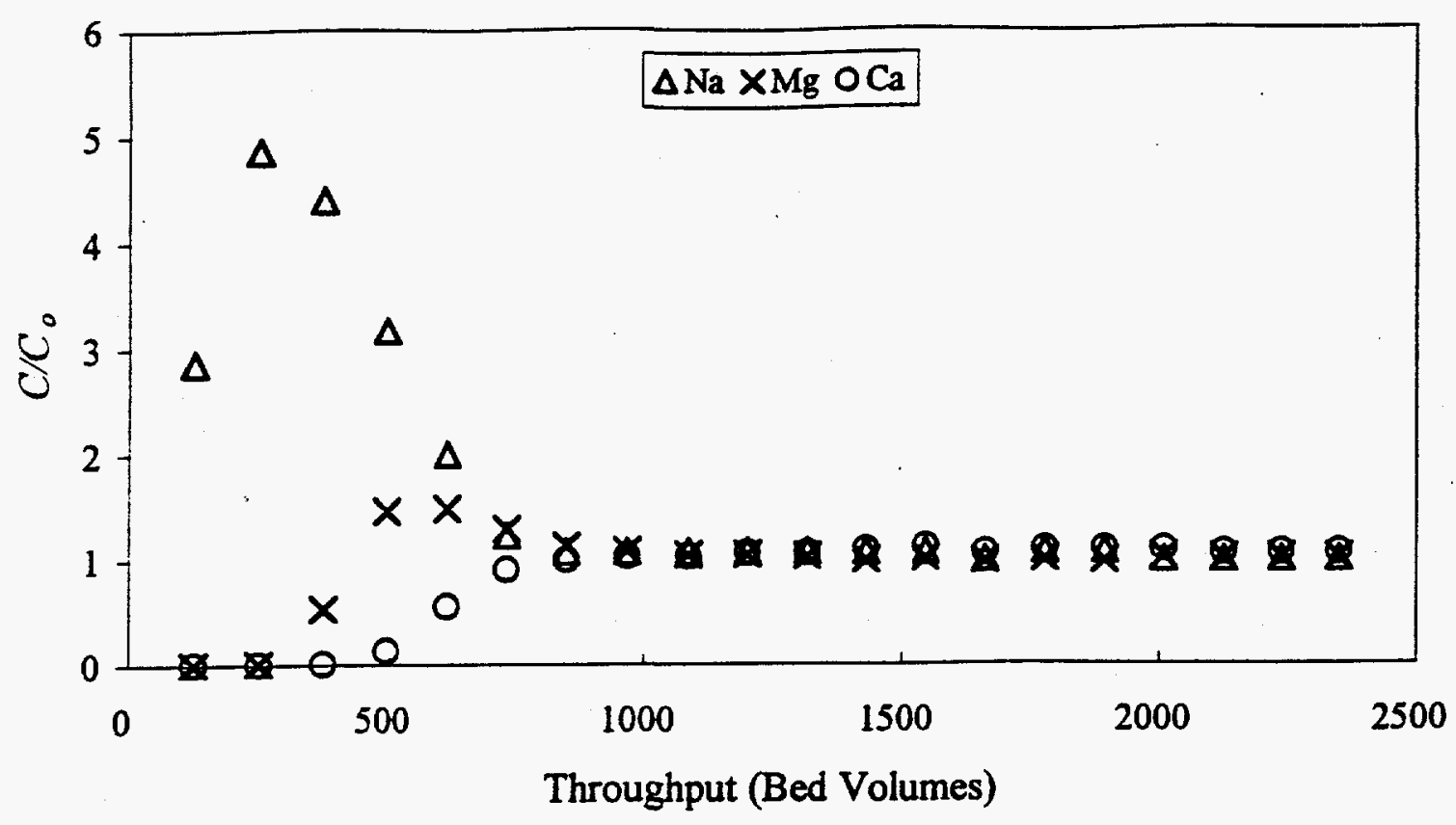

Figure 6. Cation breakthrough curves on chabazite zeolite.

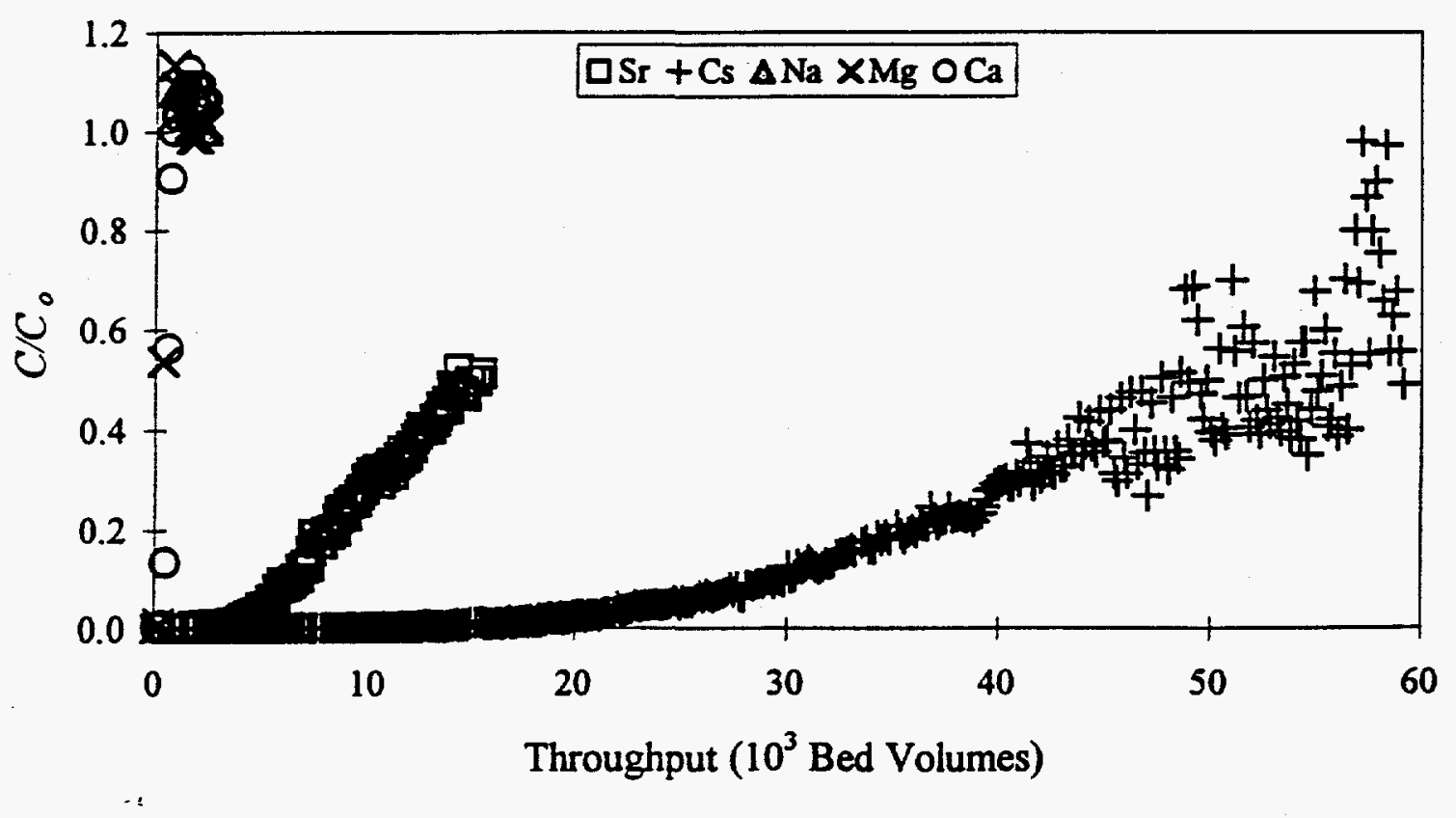

Figure 7. Strontium and cesium breakthrough curves on chabazite zeolite. 
The column experiment was run with the PWTP simulant feed stream, whose concentrations were given in Table 2. The column properties, flow rates, and cation concentrations were identical to those used in the zeolite column test, in order to make possible direct comparisons of the two ion-exchange materials.

A 1-cm-diam column containing about $2 \mathrm{~g}$ of Hydrogen-CST was used to treat wastewater simulant. Cation breakthrough was followed by ICP analysis of the effluent, and the radiostrontium and cesium breakthrough was monitored using gamma spectrometry. The height of the CST bed in the column was $4.85 \mathrm{~cm}$, and the bed volume was $3.81 \mathrm{~mL}$. At a nominal simulant flow rate of $1.2 \mathrm{~mL} / \mathrm{min}$ (19 BV/h), the superficial velocity through the bed was $1.53 \mathrm{~cm} / \mathrm{min}$. The nominal solution residence time in the column was about $3.2 \mathrm{~min}$. A column void volume of 0.6 was assumed.

The column was run for a total of 10 months; a total of 120,000 BV were processed by the $3.8 \mathrm{~mL}$ column during this time. Only limited maintenance of the column system was required. This included the replacement of worn peristaltic tubing, flow lines, and the prefilter that had evidence of algae growth.

Figure 8 shows the breakthrough curves of the cations $\mathrm{Mg}, \mathrm{Ca}$, and $\mathrm{Na}$. All reached $50 \%$ breakthrough at under $1300 \mathrm{BV}: 160,800$, and $1225 \mathrm{BV}$ for $\mathrm{Mg}, \mathrm{Ca}$, and $\mathrm{Na}$, respectively. Figure 8 also shows the potassium breakthrough curve, where $50 \%$ breakthrough occurred at $16,000 \mathrm{BV}$. All cation breakthrough curves have a sharp front (i.e., initial part of the breakthrough curve) and a diffuse, or drawnout, tail. The shape of the curves is indicative of a slow approach to equilibrium concentration, which may signify the rate-controlling step is diffusion of the species in the solid, particle phase as opposed to a ratecontrolling step in the liquid phase. ${ }^{11}$

The CST selectivity of cesium over strontium is demonstrated in Fig. 9, which shows the beginning of strontium breakthrough. Cesium breakthrough was not seen, even up to $120,000 \mathrm{BV}$ (10 months operation). Strontium breakthrough was approximately $15 \%$ at $120,000 \mathrm{BV}$. The $\mathrm{pH}$ was tracked over the length of the column test. Based on the effluent $\mathrm{pH}$ and sodium concentration, the functionality of the Hydrogen-CST in the column was calculated as function of column throughput. Equilibrium calculations indicate that the Hydrogen-CST is initially in the form of $\mathrm{H}_{3}-\mathrm{CST}$. In continuous contact with a sodiumbearing feed stream, the CST is completely converted to $\mathrm{H}_{2} \mathrm{Na}-\mathrm{CST}$ by $1100 \mathrm{BV}$. Therefore, sorption of $\mathrm{Ca}, \mathrm{Mg}$, and $\mathrm{Na}$ is accomplished when the column is primarily in the trihydrogen form. Sorption of $\mathrm{K}, \mathrm{Sr}$, and Cs takes place when the CST is present as the monosodium form.

The breakthrough curves in Figs. 8 and 9 support the initial batch findings for selectivity of CST in process wastewater simulant in the following order, with the addition of potassium and sodium: $\mathrm{Mg}<\mathrm{Ca}<\mathrm{Na}<\mathrm{K}<\mathrm{Sr}<\mathrm{Cs}$. 


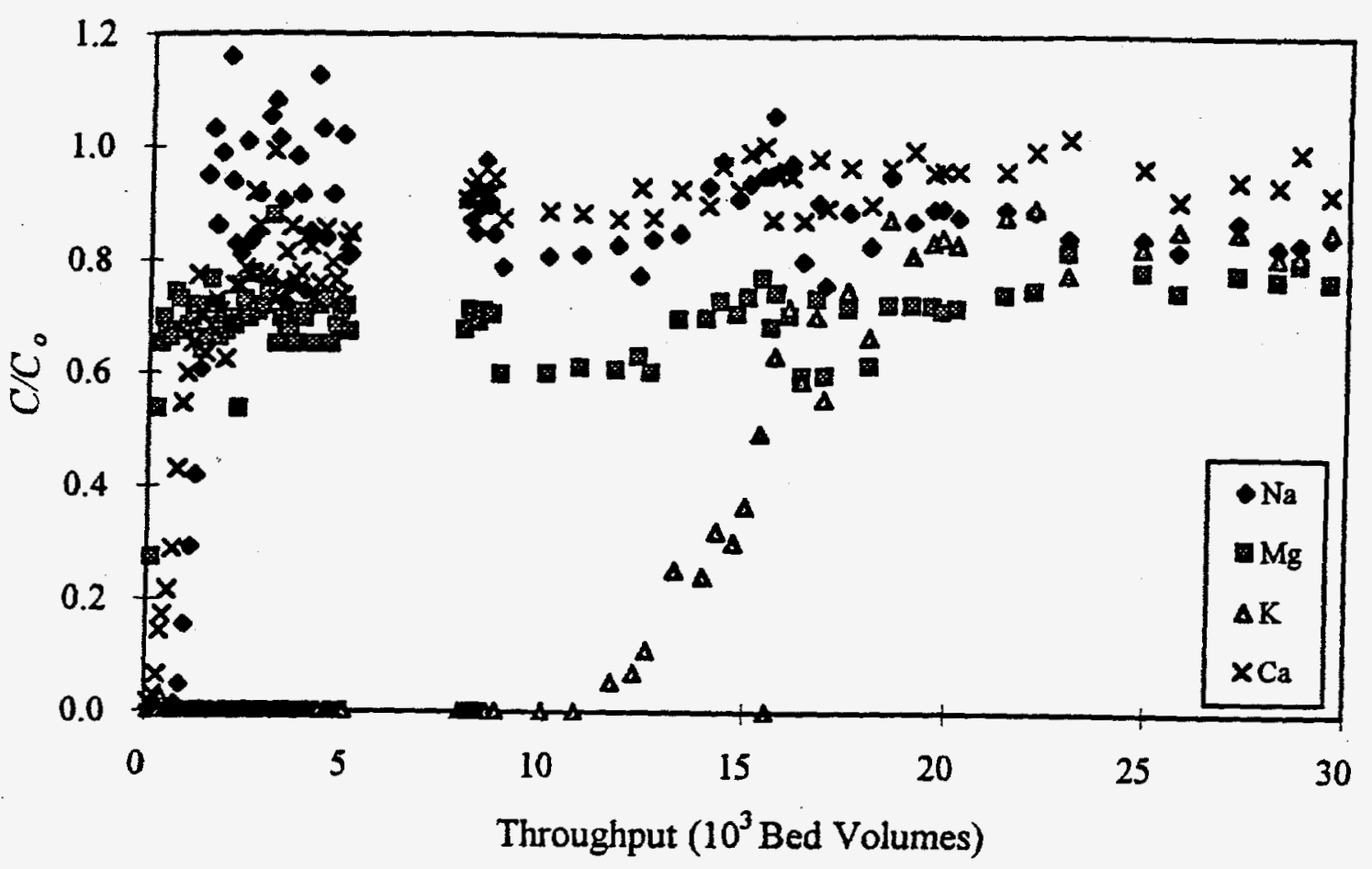

Figure 8. Cation breakthrough curves on CST, IONSIV IE-911.

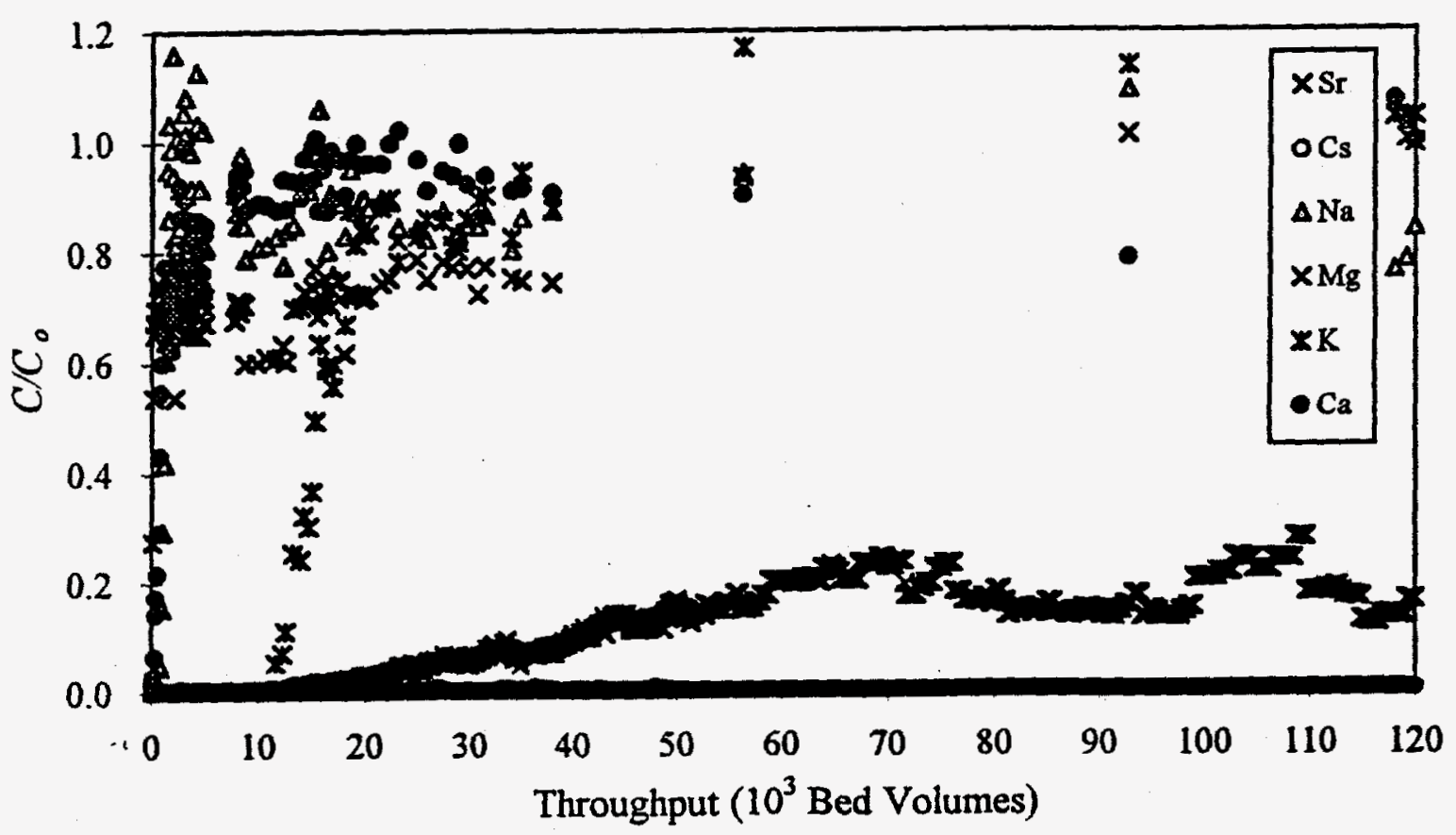

Figure 9. Strontium and cesium breakthrough curves on CST, IONSIV IE-911. 


\section{CONCLUSIONS}

A comparison of $\mathrm{Cs}$ and $\mathrm{Sr}$ distribution coefficients (or maximum $R_{\mathfrak{y}}$ ) for CST and baseline zeolite in batch studies was made in Table 3. Table 4 gives the distribution coefficients (maximum sorption ratios) as determined in the column studies. The values for both Cs and Sr on CST were estimated.

Table 4. Distribution coefficients for cations on chabazite zeolite and IONSIV IE-911.

\begin{tabular}{|c|c|c|}
\hline \multirow[b]{2}{*}{ Cation } & \multicolumn{2}{|c|}{ Column distribution coefficients $(\mathrm{L} / \mathrm{kg})$} \\
\hline & Chabazite zeolite & $\begin{array}{l}\text { Crystalline silicotitanate } \\
\text { (IONSIV }{ }^{\oplus} \text { IE-911) }\end{array}$ \\
\hline Calcium & 600 & 800 \\
\hline Cesium & 53,000 & $2,300,000^{\circ}$ \\
\hline Potassium & ND & 16,000 \\
\hline Magnesium & 400 & 160 \\
\hline Sodium & $<100$ & 1200 \\
\hline Strontium & 15,800 & $169,000^{\circ}$ \\
\hline Selectivity in PWTP simulant & $\mathrm{Na}<\mathrm{Mg}<\mathrm{Ca}<\mathrm{S} r<s$ & $\mathrm{Mg}<\mathrm{Ca}<\mathrm{Na}<\mathrm{K}<\mathrm{Sr}<<\mathrm{Cs}$ \\
\hline
\end{tabular}

${ }^{a}$ Estimated based on column and batch studies.

$\mathrm{ND}=\mathrm{Not}$ determined.

Both exchangers sorb calcium to approximately the same degree. Magnesium is more strongly exchanged on zeolite compared with CST by almost a factor of three. Potassium appears to be strongly exchanged on the CST, with a column distribution coefficient of about $16,000 \mathrm{~L} / \mathrm{kg}$. Data for potassium exchanging on the zeolite are not available because the potassium concentration in the simulant was below the ICP detection limit at that time.

The $K_{d}$ 's measured during batch tests with CST show an enormous distribution of ${ }^{137} \mathrm{Cs}$ on the solid in equilibrium with the liquid. This affinity for ${ }^{137} \mathrm{Cs}$ is supported by the column work. Breakthrough of cesium was not obtained in the CST column study. A total of $120,000 \mathrm{BV}$ were passed through the CST bed, without even $1 \%$ breakthrough noted. Comparably, in the zeolite small-column test, with all 
test conditions similar (PWTP simulant feed, flow rate of $1.2 \mathrm{~mL} / \mathrm{min}$, same column size, same volume of exchanger, etc.), $1 \%$ cesium breakthrough occurred at $15,000 \mathrm{BV}$ and $50 \%$ breakthrough occurred at $50,000 \mathrm{BV}$.

Strontium breakthrough of $1 \%$ occurred at $14,000 \mathrm{BV}$ in the CST study. At the end of the test, $C / C_{0}$ for strontium (Fig. 9) was about $15 \%$ at $120,000 \mathrm{BV}$. The baseline zeolite performed much less effectively for strontium removal, with $1 \%$ breakthrough occuring at $3000 \mathrm{BV}$, and $50 \%$ breakthrough at $15,000 \mathrm{BV}$.

Analysis of this incomplete strontium breakthrough data suggests a maximum possible sorption ratio of about $169,000 \mathrm{~L} / \mathrm{kg}$ at $50 \%$ breakthrough. This is about 1.8 times higher than the $R_{8}$ obtained from batch data. Applying that factor to the maximum cesium $R_{3}$ obtained in batch experiments suggests that $50 \%$ breakthrough would not occur until over $2 \times 10^{6} \mathrm{BV}$ had been processed, almost 17 years of operation!

Physically, the stability of the CST material has far exceeded that of the zeolite. No problems with plugging or channeling were noted with the CST after ten months of operation, whereas the zeolite produced fines that cemented together and prevented column flow by $50,000 \mathrm{BV}$, or six months operation.

Many factors must be included in a cost comparison of the two sorbents. While a direct comparison of the initial cost of the sorbents undoubtedly points to the much less expensive sorbent, zeolite, as the most cost effective choice, the cost of operating columns (i.e. column sluicing and changeout of sorbent) and the disposal of the loaded sorbent all must be taken into consideration. These costs normally far outweigh the cost of the ion-exchange material. Also, since each waste stream has different cation compositions, and therefore different loading capacities for cesium and strontium, the economics must be calculated and compared on the basis of the waste stream being treated.

Funding provided by the Environmental Management Office of Science and'Technology Efficient Separations and Cross Cut Program 


\section{REFERENCES}

1. UOP Product Information, "IONSIV॰ IE-910 Ion-exchanger Series," UOP Molecular Sieves, Mt. Laurel, N.J.

2. Testing Sieves and Their Uses, Handbook 53, 1962 ed., W. S. Tyler Company, Cleveland, Ohio.

3. Z. Zheng, C. V. Philip, R. G. Anthony, J. L. Krumbansl, D. E Tradell, and J. E. Miller, "Ion Exchange of Group I Metals by Hydrous Crystalline Silicotitanates," Ind. Eng. Chem. Res. 35, 4246-4256 (1996).

4. Z. Zheng, R. G. Anthony, and J. E. Miller, "Modeling Multicomponent Ion Exchange Equilibrium Utilizing Hydrous Crystalline Silicotitanates by a Multiple Interactive Ion Exchange Model," Ind. Eng. Chem. Res. 36, 2427-2434 (1997).

5. R. G. Anthony, R. G. Dosch, D. Gu, and C. V. Philip, "Use of Silicotitanates for Removing Cesium and Strontium from Defense Waste," Ind. Eng. Chem. Res. 33, 2702-2705 (1994).

6. EPA program web site: http://www.cee.odu.edu/cee/model/minteq.html

7. D. T. Bostick, W. D. Amold, Jr., B. Guo, M. W. Burgess, D. R. McTaggart, and P. A. Taylor, Evaluation of Improved Techniques for the Removal of ${ }^{90} \mathrm{Sr}$ and ${ }^{137} \mathrm{Cs}$ from Process Wastewater and Groundwater: FY 1995 Status, ORNL/TM-13099, Oak Ridge National Laboratory, Oak Ridge, Tenn., March 1996.

8. D. T. Bostick and B. Guo, Evaluation of Improved Techniques for the Removal of Fission Products from Process Wastewater and Groundwater: FY 1996 Status, ORNLTM-13306, Oak Ridge National Laboratory, Oak Ridge, Tenn., 1997.

9. D. T. Bostick, W. D. Amold, Jr., P. A. Taylor, D. R. McTaggart, M. W. Burgess, and B. Guo, Evaluation of Improved Techniques for the Removal of ${ }^{90} \mathrm{Sr}$ and ${ }^{137} \mathrm{Cs}$ from Process Wastewater and Groundwater: Chabazite Zeolite Baseline Study, ORNL/TM-12903, Oak Ridge National Laboratory, Oak Ridge, Tenn., April 1995.

10. S. M. Robinson, T. E. Kent, W. D. Amold, and J. R. Parrott, Jr., The Development of a Zeolite System for Upgrade of the Process Waste Treatment Plant, ORNL/TM-12063, Oak Ridge National Laboratory, Oak Ridge, Tenn., October 1993.

11. D. M. Ruthven, Principles of Adsorption and Adsorption Processes, John Wiley and Sons, Inc., New York, 1984. 